\title{
Improve Performance or Corruption Motivation in Beyond Budget Implementation, Survey in Public Sector Organizations
}

\author{
Abdulzahra S. Alrawazqee* Prof. Tamara Tsatkhlanova \\ Economic college, "Kalmyk State University",Elista, Russia
}

\begin{abstract}
This paper aims to determine possibility beyond budget implementation in public sector organization which submissive to federal government budget instructions, this budget as an act should be followed, by those organizations committed by financial ministry planning. We have discussed tow thinking groups. First, a group that performs the use of the budget as a tool for financial control, they criticize the use of beyond budget, (Horngren et al., 2004). second, group ague adoption of the budget in the control is method has become useless, beyond budget provide better utilization resource and best regarding with market opportunities and problems (Hope and Fraser, 2003), (Hansen et al., 2003). We interviewed accounting managers, auditing managers, and their assistance in research sample organizations which owned by government. Interviews were conducted from a managerial viewpoint with the accounting managers and their assistants, as well as from a control viewpoint with auditing managers, in order to distinguish between areas of corruption and financial performance motivation. Interview has done in December 2020 to February 2021, in public sector organization in Al-Najaf city in Iraq. We found public sector organization possible to implement beyond budget. However research sample organizations need to improve their level of controlling and efficiency for employees otherwise ignore traditional budgets, will cause corruption and authority misusing. Implementation beyond budgeting helps them to provide solutions the problems facing activities which unexpected.
\end{abstract}

Keywords: $\backslash$ beyond budgeting, performance improving, reduce corruption, controlling

DOI: $10.7176 / \mathrm{RJFA} / 12-6-04$

Publication date:March $31^{\text {st }} 2021$

\section{Introduction}

Budgets considered as a complex set of future plans and methods of implementing them according to monetary standards, thus leading to the formulation of future policies for the organization's activities and their realization, based on predictions from set of historical factors surrounding the environment of that organization. Sometime these factors can be changed quickly and unexpectedly. In this case, the traditional budget will be Inappropriate, to utilization market opportunities during best performance to maximize profit.

Owners seek to increase controlling over operation expenses of companies at all levels; using all the possible ways and technics, intensity of market competition is perhaps one of the main reasons for tightening supervision to obtain the best possible financial performance. As Khalil, (2019) indicated budgets are the most important method to controlling cash flow by determination authority for each level of management for next period which is usually one year. However the management aims to reaching the highest level of financial performance, which leads to increased profits accordingly.

According to above, full commitment to budgets may loss leading of some opportunities or failure to exploit them in a timely manner, fast computation in global market needs to be ready for any changing commercial environment and distribute responsibly in a matter to change a plan within the required time. This led to the emergence of the need beyond budget. However, many advocates of what is beyond budget have made many efforts to develop its concept, moreover many companies prefer beyond budget model to improve their performance and sufficient of customers with shareholder, Bogsnes (2016), because their view point is modification powers for lower level management will be required.

While critics of behind budgeting see traditional budget remains the main factor for monitoring, planning and drawing future policies, it cannot be completely dispensed like Lambe et al, (2015).

government budget has multiple level of cash disbursement authority in implementing the elements of the operating budget, and its instructions are more stringent, sometime it face expected events or crises needs to fast reaction, budget $\mathrm{s}$ item changing is not allowed in any reasons without approval of financial ministry which required long time and procedure, beyond budget solve this problem to face any unexpected case, and it helps to provide better services to public, in other hand, government budget manipulation authority maybe lead to corruption when it became exist.

This research will discuss the adopted possibility of beyond budget in governmental organizations, in order to adaptive budget with operation activities, what are the authority powers that can be granted to lower administrative levels during operational activities? And, it will discuss the areas of beyond budget implementation with money protect from any expected corruption resulting of beyond budget implementation. Information resource will be obtained from interview with accounting managers, their assistance and auditing managers in 
different sectors of governmental organizations in Al-Najaf city.

Advocates beyond budgeting claim to be followed in privet sector enterprises under the pretext that traditional budget has become unsuitable controlling and planning tools and cannot be adopted during unexpected events. This paper investigates respondents whether depend beyond budgeting in public sector enterprise give same result in privet sector or will lead to corruption and misusing authority.

\section{Literature review}

\section{2-1- Beyond budget}

The term Beyond Budgeting recently has been used, which is used first time in Swedish Handelsbanken late 1970s, beyond budget means beyond traditional budget to adoptive the financial plane for required procedures resulting of the environmental market changes. It doesn't refers for budgeting only, Budgeting is a common tool used by traditional command and control management, "Beyond" means beyond that traditional management model, (Jutta \& John,2018). Its concept comes from moving 'beyond' control and command toward a more adoptive management, (Winnie at el, 2017).

The need for beyond budget has increased as a result of strict instructions in the traditional budget, and the inability to change between its elements during operational periods, the concept of beyond budgeting originated in the belief that budgeting processes were too rigid and unresponsive for companies competing in rapidly changing environments (Hope \& Fraser, 1997). The traditional budget is rigid and unresponsive to strategic changes and dealing with unexpected events or helps to waste opportunities or reduce the benefit from their occurrence, and being disconnected from strategy and reinforcing silos within the organization, according (Bourmistrov \& Kaarboe, 2013; Hansen, Otley, \& Van der Stede, 2003; Player, 2003; Robert, 2006).

Some researchers believe that is a model beyond budget as a more appropriate and effective administrative alternative based on making the required decisions (Martin \& Nevill, 2019). Jeremy \& Robin (2001) State that beyond budget is release capable people responding the changes top- down performance contract to apple them using knowledge resources within a management leading win computation and satisfying customer, its model addresses big and important issues, and the principles have developed over time (Bogsnes, 2016), (Jeremy \& Robin, 2001).

Implementation of beyond budgeting requires confidence in employees who will be empowered to adjust the budget in addition to accounting managers skills in making appropriate decisions. Hope and Fraser (2003) cite the radical decentralization philosophy of Jan Wallander as their greatest inspiration for their model of Beyond Budgeting. Moreover, they mentioned that it is important to have an ability to transfer authority from the central system and distribute it to the operational managers according to their decision-making position, and giving them the authority to use their judgment and initiative to reach their goals without being constrained by budgetary limits and specific plans in order to successful beyond budget implementation, (Bogsnes, 2016 \& Merchant \& Van der Stede, 2017).

Juhui el at (2015) mentioned that it is a management philosophy that makes dependence on administrative performance based on advanced principles. Creating of culture and motivation value to do the best, the one of importance factor to implementation beyond budget,(Heinzelmann, 2019).

The following figure (1) shows the most important differences between the traditional budget and beyond budget, where it can be seen that the traditional budget is characterized by strict powers that are not able to change despite environmental changes, for industry age considered key factor. However in information age, changes always are surprising and leading to unperfected fixed budget, as Juhui et al, (2015) said it sucks the energy, time, fun, and big dream out of an organization, its main goals controlling and implementation annual strategic plan for top management. When beyond budget can be change in compliance with competitive requirements and the desire to maximize profits, its main goal to adaptive management process with market required changes. It is appropriateness with information age. 
Figure1. Medium-Term Evolutionary Change Process

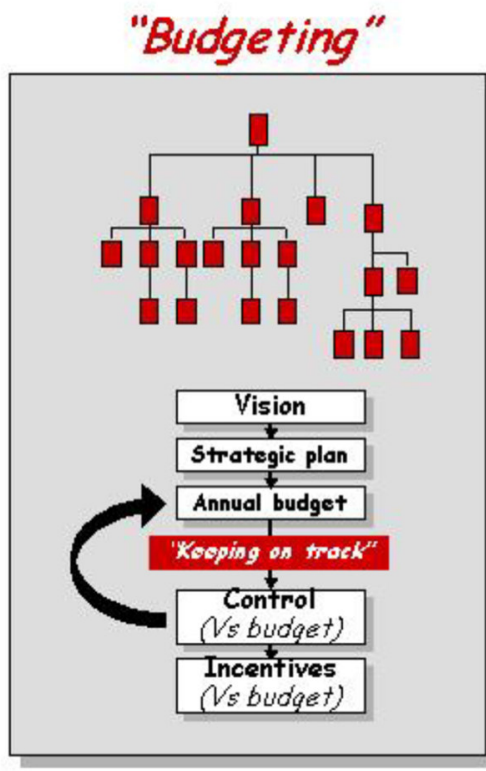

\section{"Industrial Age"}

"Devolution"; Empowerment of locel monogers Adoptive Monggement Prozesses

Medium-term evolutionary change process
"Beyond Budgeting"

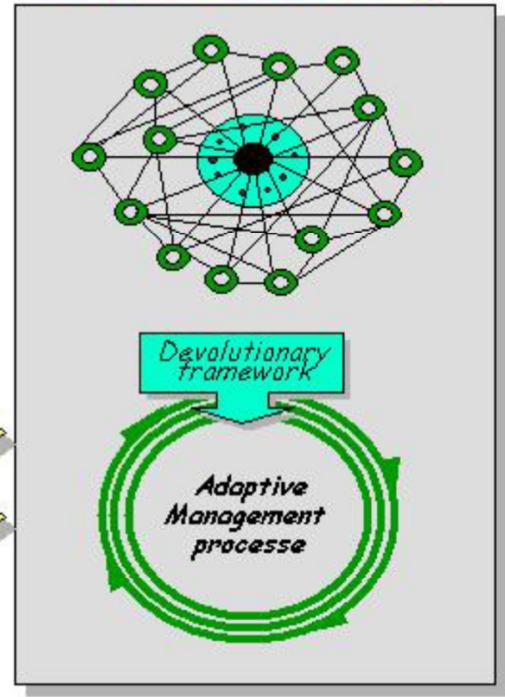

\section{"Information Age"}

\section{Source, Juhui et al (2015)}

Based the above we can mention advantages of beyond budget implementation for public sector organizations as a follow:-

1- More flexible, administration can rotate between budget $\mathrm{s}$ items, based on customer demand and environment condition.

2- self-controlling and organization, In order to improve financial management performance and move management from hierarchical to horizontal model that depends on motivating employees to provide good performance and enabling them to make decisions.

3- Getting rid of fixed performance contracts that managers depend on in the traditional budget system and as some critics consider it to be among the disadvantages of the centralization system. According to the critics, budget-based performance management is the wrong way to provide leadership to an enterprise and to control the progress made toward reaching its goals.

4- Maximization possible reward and satisfaction for customer and owners in addition to provide better cervices for public.

5- Utilize market competition through continue changing strategy.

6- Address unexpected problems in the time it happened.

7- Optimization of resources in line with operational conditions.

\section{2-2- principles of beyond budget}

According Beyond Budget Roundtable (BBRT) research it has two principle gropes first, process principles which support adaptive management process in order to get high responsible in their competition environment and customer needs in an entity. Second, leadership principles, which supports greater decentralization to increase team's responsibility finally, gets more satisfaction of customer, (Bunce, 2004, Heinzelmann, 2019, Martin \& Nevill, 2019). This term will be explained in the following appendix (1):- 
Appendix 1. Beyond Budgeting-Principles for Adaptive Performance Management

\begin{tabular}{|l|l|l|l|}
\hline Performance & Leadership principles improve culture \\
\hline Goals & $\begin{array}{l}\text { Set aspirational goals aimed at } \\
\text { continuous improvement, } \\
\text { not short-term fixed targets }\end{array}$ & $\begin{array}{l}\text { Customer } \\
\text { Relative performance, } \\
\text { not on meeting fixed targets }\end{array}$ & $\begin{array}{l}\text { Focus everyone on improving } \\
\text { customer outcomes, } \\
\text { don't micro-manage them }\end{array}$ \\
\hline Rewards & $\begin{array}{l}\text { Make planning a continuous and } \\
\text { inclusive process, not a top-down } \\
\text { annual event }\end{array}$ & Performance & $\begin{array}{l}\text { Create a network of teams } \\
\text { accountable for results, } \\
\text { not on hierarchical relationships }\end{array}$ \\
\hline Controls & $\begin{array}{l}\text { Base controls on relative key } \\
\text { performance indicators (KPIs) and } \\
\text { performance trends, } \\
\text { not budget variances }\end{array}$ & Freedom to act \\
the marketplace, not a central plan \\
Resources & $\begin{array}{l}\text { Make resources available as needed, } \\
\text { just in time, not just-in-case }\end{array}$ & $\begin{array}{l}\text { Give teams the freedom and } \\
\text { capability to act, not centralized } \\
\text { functions }\end{array}$ \\
\hline $\begin{array}{l}\text { Co- } \\
\text { ordination }\end{array}$ & $\begin{array}{l}\text { Co-ordinate } \\
\text { interactions dynamically, } \\
\text { not through annual budgets }\end{array}$ & $\begin{array}{l}\text { Base governance on clear values } \\
\text { and boundaries, } \\
\text { not detailed rules and regulations }\end{array}$ \\
\hline
\end{tabular}

Resourse :- Martin \& Nevill, 2019.

Robert had been classified beyond budget principles into two categories viewpoint of management and viewpoint of controlling, from the management viewpoint provide the change of entity culture to better and make controlling more flexible during following idea :- (Robert, 2006) base of this opinion all of (Daum, 2002; Hope and Fraser, 2003; Pfläging, 2003).

1- Freeing employees and managers from working with dissatisfaction to innovative work on the basis of motivation.

2- Establish profitability centers in order to allocate responsibilities among managers, and to promote decentralization in taking the necessary decisions, within an environment characterized by full coordination between administrative levels.

3- Through decentralization of decision-making and performance responsibility, and empowering managers \& employees

4- Apply the leadership and support method by not interfering with the upper management in the subproblems unless the lower management requests them to solve a problem.

5- By riling on internal and external market to coordinate the firm s activities.

6- The corporation can achieve the most transparency through the right information at the right time and place

From controlling viewpoint getting more performance, thereby creating necessary preconditions for a more flexible, innovative, and frugal organization, through the following mentions:-

1- Instead of relying exclusively on budget targets, company plans and monitors performance through nonmonetary indicators.

2- For control purposes, the company directs self-regulation rather than specifying expected profits and costs.

3- The company put down future visions that include all operational levels rather than defining internal functions and visions.

4- The entity should reliance on the control system by relying on the outputs-oriented process in the budgeting and planning instead of the input- cost oriented categories.

5- The organization should adopt a dynamic period, according to what the production processes require, such as a month or a quarter, instead of the traditional period, which is usually a year.

6- Company should integrate its operation budget with strategic planning instead of creating the budget far from the budget in order to implement the strategic plan in the best possible way.

7- Allowing managers to allocate resources according to business requirements leading to the creation of short budgets with a global character.

\section{2-3- controlling technique}

Budgets have historically played key role in management control. Theresa \& Murray, (2010) have stated the majority firms continue use budgets for controlling and added value purpose. Lamble et al,(2015) during their survey on organizations owned for government. Previously traditional budget is used for controlling and expenditure allocation, when entered international business environment require controlling budget to achieve its 
goals in best performance.

While for quite a long time the budget was considered one of the crucial management tools, (Josep, 2016). Moreover, some relative researchers believe the budgeting in explanation of financial plane for an enterprise and important controlling technique for management, like Gordon and Shillinglaw, (1964). According to (Josep, 2016), Hansen \& Van der Stede (2003), that feel budget is important control system. While, given today's advances in management tools, indices that are broader than the merely financial numbers, may indeed be, and often are, very useful. We have to be careful though, because there are clear dysfunctional (or even perverse) consequences of performance measures when they are used mechanically and have an incentive payment automatically associated, Rosanas \& Velilla, (2005); Cugueró el at (2016).

Based on the above, move to beyond budget reduces the controlling role whether internal or external, which lead to corruption motivation especially in public sector organization. Other researchers believe that the use of beyond budgeting cannot be completely dispensed with the traditional budget, either by combining the two budgets or developing the traditional budget to be in line with market requirements, (Goode \& Malik, 2011, Otley, 2008, Dugdale \& Lyne, 2014, ), Its application in large complex organizations also requires more organizing and coordinating of operations, ( Martin \& Nevill, 2019). However, Winnie et al (2017) have been concluded that the budget can be abandonment by activating decentralization and bypassing controlling on the basis of the budget, then divided beyond budgeting implementation into four modes of administrative performance, which are the better budget, advanced budget, restrictive budget, and non-budget.

We can be observed by above, may traditional budget abandonment gives motivation for corruption widely, however beyond budget advocates are seeing its implementation required developing employees abilities, skills, responsibilities and cooperating, that lead to developing the controlling system to face of corruption and other illegal manipulation, (Niels \& Per,2014, Martin \& Nevill, 2019, Winnie et al,2017). Winnie et al (2017), have state the four modes to adaptive performance management reflect different approaches for dealing with environmental uncertainty. Positioning non-budgeting as one mode and identifying alternate modes of adaptive performance management provides a basis for comparing and understanding the changes organizations make to move beyond budgeting.

Based on the above, we can divide the Beyond Budget approach into two ideas approaches. First, they are the advocates of beyond budge, like Hope and Fraser, (2003) and others, who see the necessity to distribute spending powers among the different levels of administration. According of them, beyond budget can be defined as a greater freedom area in making financial decisions that helps to increase the efficiency and effectiveness of employees within the organization in carrying out their responsibilities in changing strategies in order to meet the requirements of the commercial environment and make better resources utilization. Second, approach of critics of beyond budget, they believe that Distributing financial empowers help increase opportunities for financial corruption, reduce financial control and achieve long-term top management programs.

\section{Mythology}

Traditional budget is used as important tool to controlling and planning in governmental organization, it is an empower act directed by federation government to the ministries and its directorates. It is impossible to be changed between the amounts which allowance from item to another only after approval financial ministry. Moreover it may not come as desired of organization managements, because of difference between top governmental management visions with actual events will be happened during a period, those events may be none expected or surprising exist.

Beyond budget can solve those problems by distributing authority among different level of management, or giving empower to lower level management set down their budget directly. However, beyond budget will create new problems of controlling and finally corruption, during interviews financial managers, their assistances and auditing managers for public sector organizations in Al-Najaf city, we discus possibility implementation beyond budgets in those organizations, and controlling degree required to its adaptation.

Those organizations including education, health, youths and sport, Governorate Office, agriculture, environmental center, planning, organization, Al Kufa University, Al Kufa cement factory, Al Najaf court and Municipality, all those organizations follow federation government budget in their operating activity, and suffer unpleasant events annually. Questions are classified into two groups, first relative performance motivation, second reduce controlling (corruption motivation), Answers of interviews are explained in the below:-

\section{3-1- performance motivation}

Organization research sample prepare budgets every year directly, then budget will be sent to financial ministry through particular ministry to collect all budgets in order to prepare federation budget, financial minister will change many items adoptive with annual government revenue and governmental center vision. Most of them adopted traditional budget. In this part of investigation will discuss questions related performance motivation with accounting managers and their assistants which are explained below. 
Education organization

They always suffer from budget which is not enough for planned activities, in another hand it comes late every year in month of March or April, which lead to decrease of accounting period that represents an obstacle in achieving projects. The respondents see beyond budget will help them to increase performance, developing efficiency and effectiveness, it enables to manipulate amounts between items where required, they have many activities relative establishing and maintenance schools, non-school teaching activities and others cannot be done in financial reasons. Those answers similar of respondents in Governorate Office, youth and sports organization, Al- Najaf court, and planning branch.

Health organization

Many health crises are faced such as coronaviruses according respondents, need different planned and non-planned programs, recently they suffer lack of finance for some budget items, which reduce some necessary health programs. Beyond budget helps obtaining financial allocations from some projects that can be postponed. General Directorate of Agriculture and environmental center

They face some events come by weather changing, changing rain rates, or some sudden environmental events, beyond budgets help to provide activities for treating in perfect matter.

Al-Kufa University

There are international and local scientific activities come suddenly but its allowance in budgets not enough some time to participate all of them. Beyond budgets help to better utilization of those programs which lead to presenting better scientific production.

Municipal departments

They use programs and performance budgeting. It is Self-financing organization, but should follow the financial ministry 's instructions, they have more financial freedom in achieving their planning programs, from other organizations, respondents see beyond budget solves a lot of operation problems, helps to introduce better performance and achieves more goals, they told a lot projects not completed because financial authority problems, like Parks, new roads paving and a lot of infrastructure projects. The most problem that can be solved is big gap between municipal planning and financial Ministry's plans within budget.

Al-Kufa cement factory

Traditional budget is prepared in factory accounting department and send to manufacturing ministry, then it will be collected with other factories budgets and sent to financial ministry, during prepare budget high proficiently and forecast level are using, according respondents, despite the big reservations in preparing the budget, the factory faces many unexpected market events such as the increased demand for cement, losing some raw materials from suppliers or frequent breakdowns that occur in heavy equipment and others, beyond budget will makes easy those events treatment.

The following figure (3) shows positive relationship between beyond budgeting adopting and performance motivation, the greater adopting on beyond budgeting, the greater performance motivate, when achieve traditional budgeting abandonment reach highest motivation level of performance, and vice versa.

Finger no. 3 show relationship between beyond budgeting implementation and motivation performance*

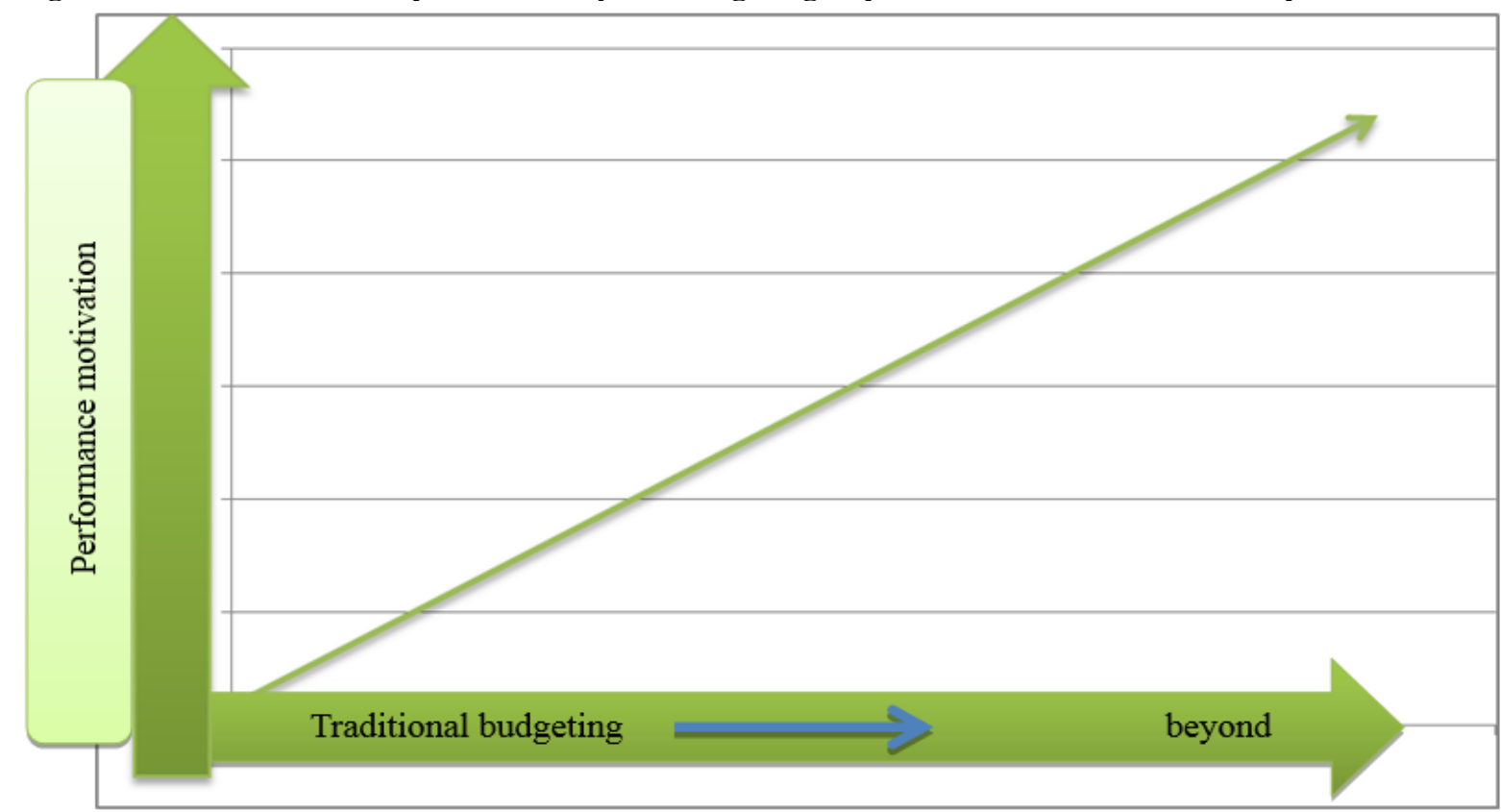

*preparing by researchers adopted respondents answer 
According respondents we can mention beyond budget helps to improve the working environment of the research sample organizations, which leads to providing better services to the public that keep pace with the current development in society. Moreover it increases flexibility of administrative financial decisions, which contribute to the promotion of changing strategies based on financial priorities and the optimal utilization of resources.

\section{3-2- decrease controlling}

Second part on investigation related with corruption motivation that came within traditional budget abandonment. Controlling managers are target respondents in sample organizations, all of them answered that abandonment of budget needs to improve the employee's efficiency of management; accounting and auditing widely, through recently condition.

Governorate Office

It is the most organization effected by political parties' manipulation at research sample organizations, and highest corruption suffering resulting of political situation in all Iraqis organizations, they explained, traditional budget ignorance will lead to increase corruption level and authority misusing at this condition. However they claim to use items budgeting manipulate authority to adopt their activities with determination of changing roles. Recently financial ministry gives authority to change between servicing, maintenance and goods purchasing items at $10 \%$ for Governors. According to respondents they need more authority like 20\% for directed managers and $40 \%$ for governors, to be parallel with increased controlling and management efficiency.

Al-Kufa cement factory

There are lots of unexpected events with lack of financial allocation, they have to ask financial ministry to take amount from other items which have funding ample to provide those events by money, indeed it takes time, but abandonment of traditional budget give opportunity to fund misusing lead corruption in recently condition, they believe empower authority for change at $20 \%$ from each item to another helps to better opportunities market utilization, moreover using this authority need to improve employees and managers efficiency along with controlling.

Figure (4) shows the positive relationship between controlling and efficiency with performance motivation during implementation of beyond budgeting, higher level of controlling and efficiency lead to achieve highest performance, when lower level of controlling and efficiency lead less performance which finally lead to corruption, can be call there is inverse relationship between controlling and corruption,

Finger no. 4 shows relationship between controlling and efficiency with motivation performance corruption

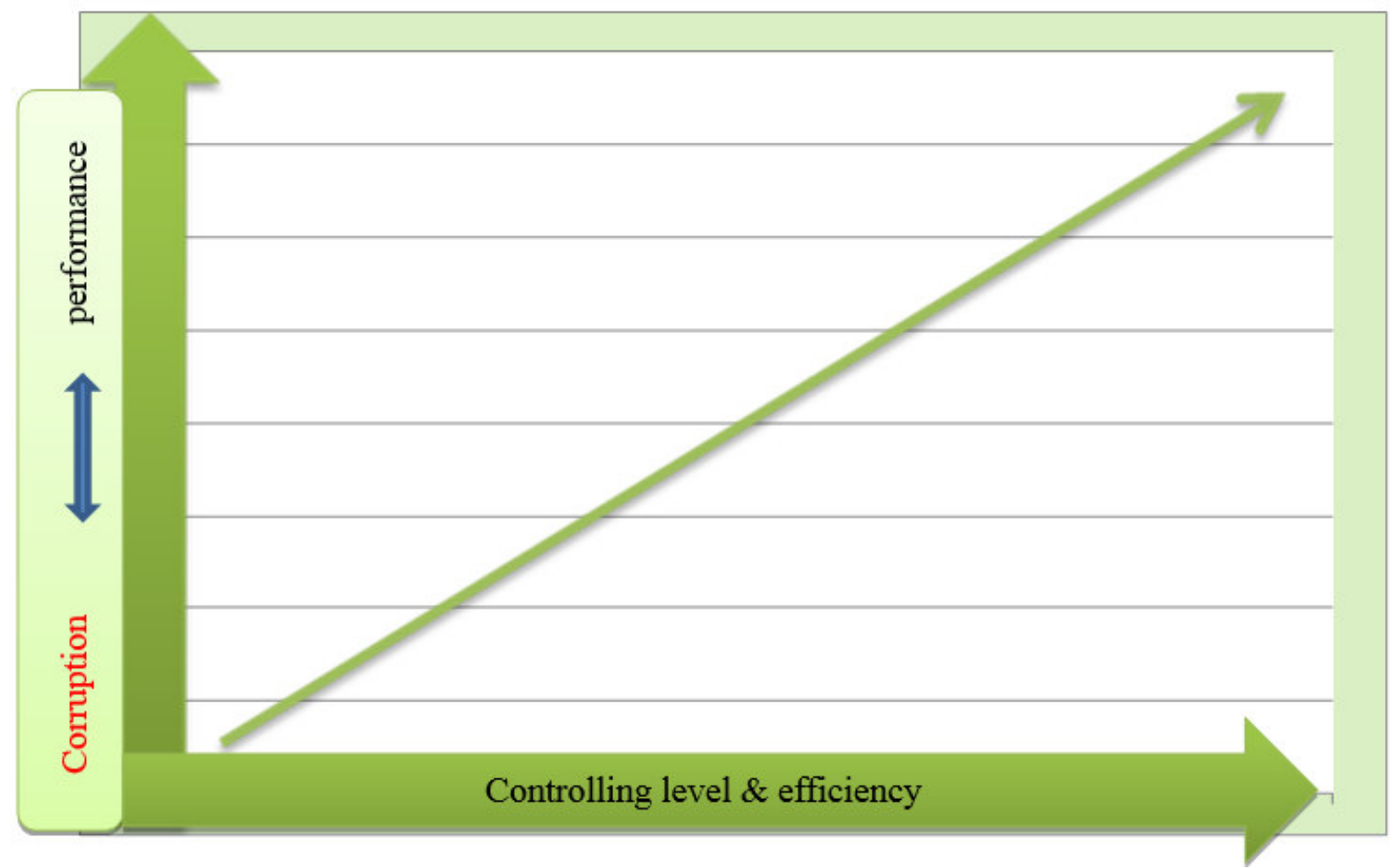

*preparing by researchers adopted respondents answer

On another hand, budget beyond give an opportunity to misusing of authority for research sample organizations, recently their control level is not ready to abandonment of traditional budget because impacts of bad political situation. We notice that there is a convergence of answers, which sends reassurance in re-directing 
questions that will lead to the same answer. In addition it is possible to generalize the results of the study to public sector organizations in other Iraqi cities.

\section{Conclusion}

For private enterprises Dileepa \& Samudrage (2018) fund that the most important reason hindering people from following budget projections is decreased awareness, complications of setting rolling forecasts, bureaucracy, difficulties in assessing team performance, dependency culture on budgets to guide and evaluate performance, dependency culture on shared services and perceiving dynamic goals as too ambiguous to set. In Theresa \& Murray (2010)comparative survey between Canadian companies grope and USA companies fund most companies suffering gaming budgets, whereas is more apparent in US companies.

Winnie, et al, (2017) fund there are four levels may be used in organization managing instant traditional budget, those are improved, selectively modified, restricted or eliminated, four models of adaptive performance management were distinguished according to these criteria, which they labeled as better budgeting, advanced budgeting, restricted budgeting and non-budgeting. When Josep (2016) saw the budget itself can't solve all management decision problems, and it needs additional variables to be controlled by other means, it can be ignore budget with almost always in the context of a thoughtfully designed budgetary system.

Nguyen et al (2018) have state although proponents of beyond budgeting have put substantial effort into developing and promoting this concept, numerous empirical studies demonstrate that many organizations being investigated would still rather improve traditional budgeting than abandon it completely. They also highlight the main criticisms of traditional budgeting, development of management control systems under beyond budgeting and factors hindering the implementation of beyond budgeting. When a coaching management style provoking empowered and accountable employees is the core of the Beyond Budgeting approach (Bogsnes, 2016).

Michal et al,(2020) found that Beyond Budgeting organizations tend to use (i) high levels of decentralization, (ii) flexible resource allocations without fixed timelines, (iii) relative target setting, and (iv) weak individual incentives. Second, we find evidence suggesting that many Beyond Budgeting implementers found it difficult to reduce the reliance on a fixed annual budget for decision making and on financial performance measures for performance evaluation. Third, we find that the likelihood and scope of BB implementation is negatively associated with the importance of long-term investment coordination.

It is known public sector enterprises differ from the private sector in terms of financing and administrative authority. Ache level of management has special empowers of expenditure. Traditional budgets considered as internal act to systematic daily operation, ache manager responsible on his area authority. However, we consider that implementing Beyond Budgeting might gain a lot of advantages especially for knowledge based organizations. But the system might be difficult to implement as it requires changes in managers and employees mindset. It seems that most organizations are not ready to stretch themselves yet. We suggest improving their controlling and efficiency. Without its improving, traditional budgeting abandonment gives an opportunity to misusing authority in research sample enterprise. However there is possibility to use traditional budget along with changing authority between its items for ache level of management around $20 \%$ to $40 \%$, the change authority instructions should preparing in financial ministry and introduced to enterprise owned by government.

\section{References}

Bourmistrov, A., \& Kaarboe, K. (2013). From comfort to stretch zones: A field study of two multinational companies applying 'beyond budgeting' ideas. Management Accounting Research, 24(3), 196-211. https://doi.org/10.1016/j.mar.2013.04.001

Bogsnes, B. (2016). Implementing Beyond Budgeting: Unlocking the performance potential. Hoboken: John Wiley \& Sons.

Bunce, P. (2004, July). The beyond budgeting journey towards adaptive management. A report on the better budgeting forum fromCIMA and ICAEW.

Cugueró-Escofet, N., Rosanas, J. (2016). The Ethics of Metrics: Overcoming the Dysfunctional Effects of Performance Measurements through Justice, Journal of Business Ethics. https://doi.org/10.1007/s10551-0163049-2

Daum, J. H.,( 2002) "Beyond Budgeting - Ein Management- und Controlling-Modell für nachhaltigen Unternehmenserfolg", Der Controlling-Berater, 7. https://docplayer.org/2255518

Dugdale, D., \& Lyne, S. (2014). Budgeting practice and organisational structure. Research Executive Summaries Series, 6(4).

Dileepa N. Samudrage\& Hansinee S. Beddage,(2018), Status and Challenges in Implementing Beyond Budgeting: Evidence from Sri Lanka, International Business Research; Vol. 11, (12), 113-126. http://dr.lib.sjp.ac.lk/handle/123456789/8519

Goode, M., \& Malik, A. (2011). Beyond Budgeting: The Way Forward? PJSS , 31(2), 207-214. 
Thomas Heupel \& SvenSchmitz,2015, Beyond Budgeting - A High-hanging Fruit The Impact of Managers' Mindset on the Advantages of Beyond Budgeting, journal Procedia Economics and Finance, Vol. (26), P 729736. https://doi.org/10.1016/S2212-5671(15)00831-X

Hansen, S. C., Otley, D. T., \& Van der Stede, W. A. (2003). Practice developments in budgeting: An overview and research perspective. Journal of Management Accounting Research, 15(1), 95-116.

Heinzelmann, R. (2019). Why does Beyond budgeting work in Scandinavian organizations?. Controlling Zeitschrift für erfolgsorientierte Unternehmenssteuerung, 31, 27-28.

Hope, J., \& Fraser, R. (2003). New Ways of Setting Rewards: The Beyond Budgeting Model. California Management Review, 45(4), 104-119.

Herman A.,(2017), Infused with value? Trajectories, discourses and institutional constructions in Beyond Budgeting diffusion, International Journal of Management Concepts and Philosophy, vol.10(2), pp. 199-225. https://doi.org/10.1504/IJMCP.2017.084059

Hope, J., \& Fraser, R. (1997). Beyond budgeting: Breaking through the barrier to the third wave. Management Accounting, Vol.75(11), 20-23.

Jutta Eckstein \& John Buck, (2018), Company-wide Agility with Beyond Budgeting, Open Space \& Sociocracy Survive \& Thrive on Disruption, Leanpub.

Jeremy H. \& Robin F. (2001), beyond budget round table, CAMI

Juhui Tian, Qian Lin, Qing Hao \& Dan Wu,(2015), The Application of the Beyond Budgeting to Organisations, An Example of Application of Borealis Company, Modern Management Science \& Engineering,V.3 (1) 6274.

Josep M. Rosanas(2016), Budgeting Beyond Budgeting: A Tool for Management, Surprise Avoidance, Trust Creation and Organizational Learning, European Accounting and Management Review · V. 3, (1), 24-44

khalil Hawraa, (2019), The possibility of developing the budget of programs and performance in government administrative units according to a proposed framework, kufa studies center journal, V. 54, 667-692.

Lambe I., Mary L. \& Theresa O., (2015), A Systematic Review of Budgeting and Budgetary Control in Government Owned Organizations, Research Journal of Finance and Accounting, 6,(6) ,1-10.

Martin M. \& Nevill S., (2019), Beyond Budgeting and Performance Management, A multiple case study of how performance is managed drawing on the Beyond Budgeting principles, University of Agder, School of Business and Law,Department of Economics and Finance.

Merchant, K., \& Van der Stede W. (2017). Management control systems. Performance measurement, Evaluation and Incentives. Fourth edition. Harlow: Pearson Education

Michal M., Kenneth A. \&Winnie O.,(2020) An Empirical Investigation of Beyond Budgeting Practices ,Journal of Management Accounting Research, Vol. 10, No. (2), https://doi.org/10.2308/jmar-19-010

Nguyen, D.H., Weigel, C. and Hiebl, M.R.W. (2018), "Beyond budgeting: review and research agenda", Journal of Accounting \& Organizational Change, Vol. 14 ( 3), pp. 314-337.

https://doi.org/10.1108/JAOC-03-2017-0028

Niels S. \& Per Nikolaj B.,(2014), Beyond Budgeting and change: a case study, Journal of Accounting \& Organizational ChangeVol. 10.( 3). 409-423.

Pfläging, N.,( 2003),Beyond Budgeting, Better Budgeting, Haufe, Freiburg,.

Rosanas, J. \& Velilla, M., (2005). The Ethics of Management Control Systems: Developing Technical and Moral Values. Journal of Business Ethics, 57: 83-96

Player, S. (2003). Why some organizations go "beyond budgeting". Journal of Corporate Accounting \& Finance, V.14(3), 3-9.

Robert C. (2006). Beyond Budgeting: Boon or Boondoggle?.journal Investment Management and Financial Innovations, 3(2), 62-76.

Theresa L. \& Murray L.,(2010), Beyond budgeting or budgeting reconsidered? A survey of North-American budgeting practice, Management Accounting Research V. 21, 56-75

Otley, D. (2008). Did Kaplan and Johnson get it right?. Accounting, Auditing \& Accountability Journal, 21(2). 229-239.

Winnie, Grady \& Chris, Akroyd \& Inara, Scott, (2017), beyond budgeting: distinguishing modes of adaptive performance management, "journal of Advances in Management Accounting" V 29, pp. 33-53. https://doi.org/10.1108/S1474-787120170000029003

\section{Acknowledgment}

I would like to express my immense gratitude towards the ministry of Iraqi education, which supported, funded and gave me an opportunity to complete this research work.

I would like to thankful my supervisor Prof. Tamara Tsatkhlanova and all member and staff of economic college in Kalmyk State University, which created a great platform to attain profound technical skills in the field of commerce, thereby fulfilling my most cherished goal and allowed me to conduct the research. 